\title{
Experimental investigation of the effects of various parameters on viscosity reduction of heavy crude by oil-water emulsion
}

\author{
Talal Al-Wahaibi • Yahya Al-Wahaibi • \\ Abdul-Aziz R. Al-Hashmi • Farouq S. Mjalli • \\ Safiya Al-Hatmi
}

Received: 28 May 2014/Published online: 22 January 2015

(c) The Author(s) 2015. This article is published with open access at Springerlink.com

\begin{abstract}
The effects of water content, shear rate, temperature, and solid particle concentration on viscosity reduction (VR) caused by forming stable emulsions were investigated using Omani heavy crude oil. The viscosity of the crude oil was initially measured with respect to shear rates at different temperatures from 20 to $70{ }^{\circ} \mathrm{C}$. The crude oil exhibited a shear thinning behavior at all the temperatures. The strongest shear thinning was observed at $20{ }^{\circ} \mathrm{C}$. A non-ionic water soluble surfactant (Triton X-100) was used to form and stabilize crude oil emulsions. The emulsification process has significantly reduced the crude oil viscosity. The degree of VR was found to increase with an increase in water content and reach its maximum value at $50 \%$ water content. The phase inversion from oil-in-water emulsion to water-inoil emulsion occurred at $30 \%$ water content. The results indicated that the VR was inversely proportional to temperature and concentration of silica nanoparticles. For water-in-oil emulsions, VR increased with shear rate and eventually reached a plateau at a shear rate of around $350 \mathrm{~s}^{-1}$. This was attributed to the thinning behavior of the continuous phase. The VR of oil-in-water emulsions remained almost constant as the shear rate increased due to the Newtonian behavior of water, the continuous phase.
\end{abstract}

Keywords Viscosity reduction - Phase inversion . Non-newtonian fluid · Oil-in-water emulsions . Heavy crude oil

T. Al-Wahaibi ( ( ) Y. Al-Wahaibi · A.-A. R. Al-Hashmi · F. S. Mjalli · S. Al-Hatmi

Petroleum \& Chemical Engineering Department, College of Engineering, Sultan Qaboos University,

P.O. Box 33, Al-Khod 123, Oman

e-mail: alwahaib@squ.edu.om

Edited by Xiu-Qin Zhu

\section{Introduction}

The flow of oil and water in pipelines is a challenging subject that is rich in physics and practical applications. The early work of Russell and Charles (1959) shows that the introduction of water into crude oil pipelines under certain conditions can reduce pressure drop and improve the transportation of the oil. This work has attracted the interest of researchers as well as the industry. The concurrent flow of oil and water is encountered in many industries such as the oil and chemical industries. Many researchers have reported the flow of both light oil and heavy oil with water in pipelines (Nädler and Mewes 1997; Angeli and Hewitt 2000; Lovick and Angeli 2004; AlWahaibi and Angeli 2011; Al-Wahaibi et al. 2012; Yusuf et al. 2012a, b). However, most of these studies have mainly focused on investigating the flow patterns, pressure drop, and hold-up of the flow.

Heavy crude and extra-heavy crude oils are becoming more important with the increasing demand for world energy, the large amount of heavy oil reserves, and the decline of conventional oils. Heavy oils have to be transported by pipelines from the well head to refineries or ports. However, transporting the heavy oil as a single phase in pipelines is very expensive because of the huge pumping costs. In some cases, it is impossible to transport these crude oils due to their low mobility and flowability and pipeline blockages from wax and/or asphaltene deposition. Different methods have been proposed to facilitate transportation of heavy crude oils. These methods include heating the crude (Yaghi and Al-Bemani 2002; Saniere et al. 2004), dilution with light oil (Yaghi and Al-Bemani 2002; Iona 1978), formation of stable oil-in-water emulsions (Yaghi and Al-Bemani 2002; Lappin and Saur 1989; Gregoli et al. 2006), or imposing core annular flow (Joseph 
et al. 1997). Yaghi and Al-Bemani (2002) have experimentally concluded that transporting heavy crude by heating or dilution is an expensive option. They found that it is cheaper to transport it as oil-in-water emulsion with an optimum oil content of around $70 \%$. Langevin et al. (2004) have reported that oil-in-water emulsions reduce the viscosity of heavy crude oils and bitumens and may provide an alternative to the use of diluents or heat. Also, hydrocarbon diluents or lighter crudes may not be available or limited, while water is readily available for emulsification. Joseph et al. (1997) have reported that transporting heavy oil as a core annular flow pattern has some operational problems especially if a start-up is required. Unlike core annular flow, the report by Simon and Poynter (1970) has shown that restarting a pipeline after an emergency shutdown and re-emulsification of oil does not pose major problems. The formation of oil-in-water emulsions can cause a reduction of oil viscosity by more than 2 orders of magnitude (Yaghi and Al-Bemani 2002). In addition, Simon and Poynter (1970) reported that since water is the continuous phase, crudes have no contact with the pipe wall and this can reduce the pipe corrosion especially for crude having high sulfur content.

Emulsions are formed traditionally by homogenization (shaking, stirring or some other kinds of intensive dynamic and/or static mixing processes). The energy input for emulsification can be significantly reduced using surfactants, which can reduce the interfacial tension (IFT). Surfactants can also stabilize the emulsions formed. Stability of these emulsions can be further enhanced using high molecular weight polymers and/or nanoparticles to induce higher rigidity and viscosity of the interfacial films. In general, non-ionic surfactants represent a good choice because they are relatively cheap and do not produce any undesirable organic residues that affect oil properties ( $\mathrm{Ri}-$ vas et al. 1998).

The subject of heavy crude oil transportation using the emulsification technique has recently attracted researchers to investigate the effect of various parameters such as surfactant concentration, speed and mixing rate, brine $\mathrm{pH}$, and oil content (Ashrafizadeh and Kamran 2010; Hasan et al. 2010; Abdurahman et al. 2012).

In this study, extensive experiments were conducted at various water contents, shear rates, temperatures, and concentrations of nanoparticles to investigate their effects on the viscosity reduction (VR) of heavy crude oil via stable emulsions. Stabilized emulsions were produced using Triton $\mathrm{X}-100$ as a surfactant. Triton $\mathrm{X}-100$ was selected as it has been widely used by different investigators and shows good stability (Ashrafizadeh and Kamran 2010; Hasan et al. 2010; Abdurahman et al. 2012).

\section{Experimental set-up}

\subsection{Materials}

Heavy crude oil, surfactant (Triton X-100), and solid nanoparticles (Aerosil 200) are the primary materials used in this study. The crude oil was obtained from the Omani heavy oil field. It has a density of $938 \mathrm{~kg} / \mathrm{m}^{3}$ at $20{ }^{\circ} \mathrm{C}$. Triton X-100 with chemical formulation of $\mathrm{C}_{33} \mathrm{H}_{60} \mathrm{O}_{10}$ was used as an emulsifying agent and an emulsion stabilizer. Triton X-100 is a non-ionic water-soluble surfactant obtained from Sigma-Aldrich Canada Ltd. Aerosil 200 was used to investigate the influence of solid nanoparticles on the VR of the emulsion and to enhance emulsion stability. Aerosil 200 is hydrophilic fumed silica with a specific surface area of $200 \mathrm{~m}^{2} / \mathrm{g}$. It is highly dispersed with spherical-shaped particles of an average diameter of $12 \mathrm{~nm}$ and a bulk density of approximately $30 \mathrm{~g} / \mathrm{L}$.

\subsection{Emulsion preparation}

Triton X-100 aqueous phase surfactant solution was prepared with tap water and used throughout the experiments. Hydrochloric acid and sodium hydroxide were used when necessary to keep the aqueous phase at $\mathrm{pH}$ 7. A known amount of the Triton X-100 aqueous surfactant solution was then transferred to a beaker. The Triton X-100 aqueous solution and crude oil were mixed using a homogenizer (Tokushu Kika Kogyo Ca. LTD) at a speed of 1,000 rpm for $30 \mathrm{~min}$ to prepare the emulsions. Stability analysis was conducted to find the surfactant concentration necessary for preparing a stable oil-water emulsion. After the minimum surfactant concentration was determined, the effects of temperature, shear rates, and solid nanoparticles on both oil-in-water emulsion and water-in-oil emulsion were investigated using this minimum surfactant concentration throughout the experiments.

\subsection{Stability of emulsion}

The stability of the emulsion was determined by measuring the amount of water separated from the emulsion after $24 \mathrm{~h}$. This was done by transferring the prepared emulsions into graduated bottles and allowing them to rest for $24 \mathrm{~h}$ to promote phase separation.

\subsection{Viscosity measurements}

The viscosity measurements were carried out using a Haake Viscometer VT500. This device is used to determine the viscosity of oil and oil-water emulsions at different shear rates and temperatures. 


\section{Results and discussion}

\subsection{Crude oil viscosity}

It is important to measure the viscosity of crude oil prior to preparing the emulsion as it will provide the basis to determine the degree of VR. In this study, the crude oil viscosity was measured in the range of shear rate from 27 to $2,700 \mathrm{~s}^{-1}$ at $20,30,40,50,60$, and $70{ }^{\circ} \mathrm{C}$. As shown in Fig. 1, the crude oil exhibited a shear thinning behavior where the apparent viscosity was found to decrease with shear rate for all the investigated temperatures. Ghannam and Esmail (2006) reported that the molecular chains in heavy crude oils would be disentangled, stretched, and reoriented with the driving force at high shear rates and this was the reason for the decrease in viscosity with shear rate. The viscosity results also revealed that the strongest shear thinning was observed at $20{ }^{\circ} \mathrm{C}$ where the viscosity of the crude decreased from 1,920 to $1,190 \mathrm{mPa} s$ at shear rates of 27 and $349 \mathrm{~s}^{-1}$, respectively. Paso et al. (2009) attributed this behavior to the interaction between the heavy components of the crude oil.

The temperature was found to have a strong effect on crude oil viscosity. At a certain shear rate, the apparent viscosity decreased sharply with temperature. The degree of this decrease was higher at lower shear rates than that at higher values (see Fig. 1). Figure 2 shows the apparent crude oil viscosity profile as a function of temperature at a shear rate of $27 \mathrm{~s}^{-1}$. The general trend of the viscosity profile can be fitted by an Arrhenius equation (Eq. 1)

$\mu=A e^{\left(E_{\mu} / R T\right)}$,

where $\mu$ is the apparent viscosity, $A$ is the pre-exponential constant, $E_{\mu}$ is the activation energy, $R$ is the ideal gas constant, and $T$ is the temperature in Kelvin.

The activation energy and the pre-exponential constant were calculated as $37.6 \mathrm{~kJ} / \mathrm{mol}$ and $3.3 \times 10^{-4}$, respectively. The apparent viscosity values were found to fit the Arrhenius model reasonably well in most cases.

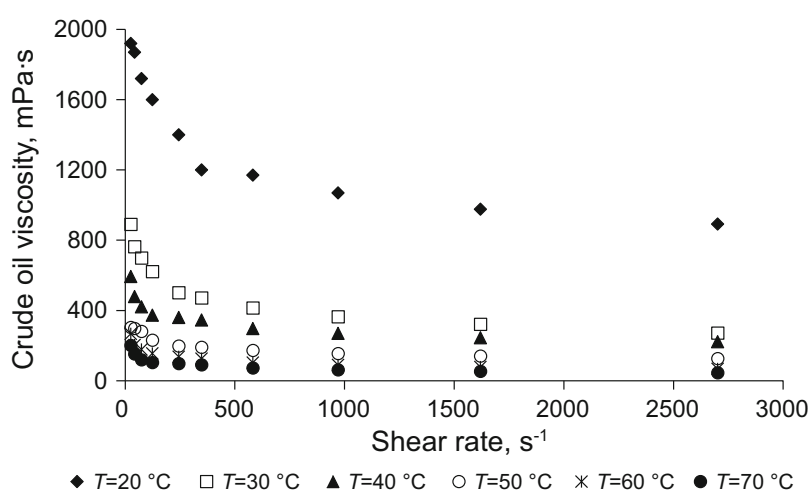

Fig. 1 Viscosity behavior of heavy crude oil at different temperatures

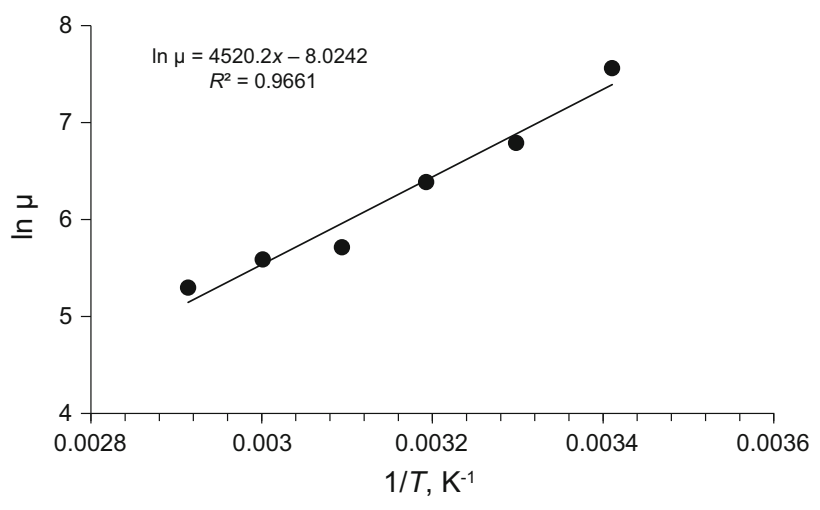

Fig. 2 Apparent viscosity of the heavy crude as a function of $(1 / T)$ with the Arrhenius model

\subsection{Emulsion stability}

The aim of this study is to investigate the influence of temperature, shear rate, and nanoparticles on the VR of stable oil-water emulsion. Therefore, it is important to find the minimum surfactant concentration required to prepare a stable oil-water emulsion. This concentration will be used throughout the study to investigate the aforementioned parameters on oil-water emulsion. The emulsion stability can be quantified using the following equation (see $\mathrm{Ab}$ durahman et al. 2012):

$$
\begin{aligned}
& \text { Emulsion stability }(\%) \\
& =100 \times\left(1-\frac{\text { Amount of separated water }}{\text { Initial water content }}\right)
\end{aligned}
$$

The effect of Triton X-100 concentration on the stability of the emulsion was examined at three oil-water contents: $40 \%$ oil $+60 \%$ water, $60 \%$ oil $+40 \%$ water, and $80 \%$ oil $+20 \%$ water. The emulsion was prepared under a constant stirring speed of $1,000 \mathrm{rpm}$ for $30 \mathrm{~min}$. Figure 3 shows the stability of the emulsions at 1,2,3, and $4 \mathrm{wt} \%$ Triton X-100 concentrations. It was clear that emulsion stability increased with increasing surfactant concentrations. This was because with increasing the surfactant concentration, the IFT between oil and water decreased. Thus, the probability for the drops to break increased, which results in more stable emulsion (Sakka 2002). No water separation was observed after 6 days for all the investigated samples when $3 \mathrm{wt} \%$ surfactant concentrations were used in the emulsion. This concentration ( $3 \mathrm{wt} \%$ ) was considered as the minimum surfactant concentration necessary to stabilize the emulsion for different oil-water contents.

\subsection{Viscosity reduction (VR)}

The effectiveness of the emulsification process in reducing the viscosity of the crude oil can be quantified by 


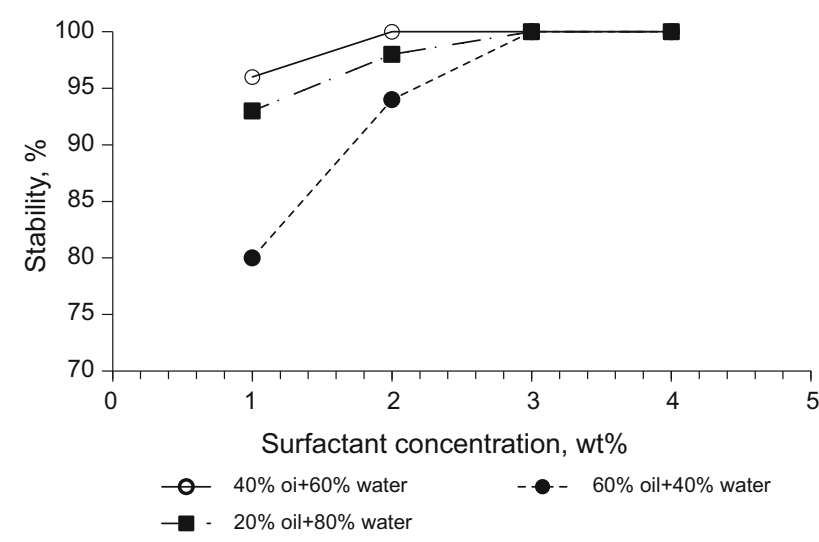

Fig. 3 Effect of surfactant concentration on the emulsion stability of different oil-water contents $\left(30{ }^{\circ} \mathrm{C}, 1,000 \mathrm{rpm}\right.$ mixing speed, $30 \mathrm{~min}$ mixing time)

calculating the viscosity difference caused by emulsification as described by the following equation:

$\% \mathrm{VR}=100 \times\left(\frac{\mu_{\mathrm{o}}-\mu_{\mathrm{o} / \mathrm{w}}}{\mu_{\mathrm{o}}}\right)$,

where $\mu_{\mathrm{o}}$ is the measured crude oil viscosity and $\mu_{\mathrm{o} / \mathrm{w}}$ is the emulsion viscosity measured at the same conditions of shear rate and temperature.

In this study, the emulsion viscosities were measured over a wide range of shear rates and temperatures. All the emulsions were prepared using $3 \mathrm{wt} \%$ Triton X-100 concentrations while stirring at $1,000 \mathrm{rpm}$ for $30 \mathrm{~min}$

\subsubsection{Emulsion and phase inversion}

Figure 4 shows the apparent viscosity of the crude oil emulsion at different water contents. In this study, the water content in the emulsion was varied from 50 to $20 \mathrm{wt} \%$ in $10 \%$ increments. At a shear rate of $27 \mathrm{~s}^{-1}$ and $30{ }^{\circ} \mathrm{C}$, the viscosity of the crude oil was $890 \mathrm{mP}$ s before emulsification with water. Adding $20 \mathrm{wt} \%$ water content, the viscosity of the oil emulsion decreased to around $410 \mathrm{mP} \mathrm{s}$ at $27 \mathrm{~s}^{-1}$ and $30{ }^{\circ} \mathrm{C}$, a VR of around $53 \%$. The viscosity of the emulsion decreased further to around $90 \mathrm{mPa} \mathrm{s}$, a VR of around $90 \%$, using $30 \mathrm{wt} \%$ water content. This sudden increase in the VR was due to phase inversion of the emulsion from water dispersed in oil (water-in-oil emulsion) to oil dispersed in water (oil-inwater emulsion). This flow behavior was in accordance with which phase is the continuous phase in the emulsion. It is well known that the emulsion viscosity is a strong function of the continuous phase and a weak function of the dispersed phase.

The effect of water content on VR for different shear rates at $30{ }^{\circ} \mathrm{C}$ is presented in Fig. 5. The VR was found to increase by increasing the water content and reached its

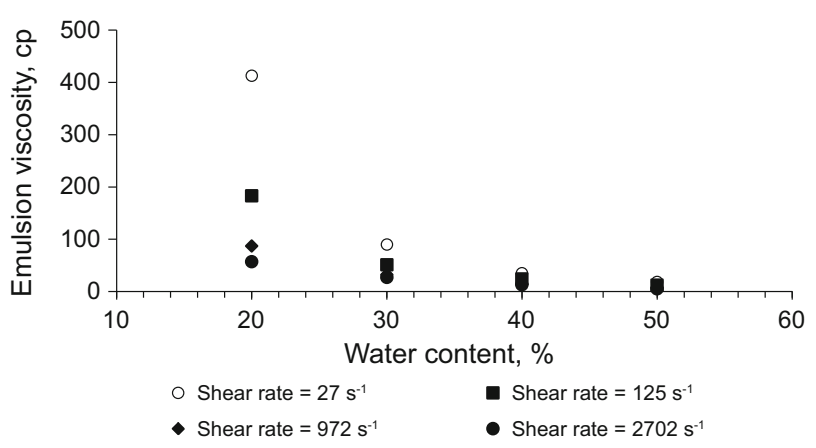

Fig. 4 Effect of water content on the emulsion apparent viscosity of Omani heavy crude oil $\left(30{ }^{\circ} \mathrm{C}, 3 \mathrm{wt} \%\right.$ surfactant concentration, $1,000 \mathrm{rpm}$ mixing speed, $30 \mathrm{~min}$ mixing time)

maximum value at $50 \mathrm{wt} \%$ water. At $20 \mathrm{wt} \%$ water content (i.e., water-in-oil emulsion), the VR could be enhanced by the increase in shear rate, whereas the VR of the oil-inwater emulsions (i.e., water content higher than $30 \%$ ) was almost independent of shear rate.

From a practical point of view and to achieve effective and economic transportation of crude oil, the emulsion viscosity should be as low as possible and the water content should be as low as possible. The experimental results revealed that the apparent viscosity of the emulsion decreased with water content. Thus, the amount of VR would increase and this can lead to lower energy consumption in pumping. In this study, the maximum oil content in the emulsion reached $70 \%$, above this value, inversion to water in oil emulsion would occur. However, due to the large pressure gradient which might occur at the phase inversion, it is important to operate well below the phase inversion point. Therefore, transportation of oil and water in pipes should be far from the phase inversion point (Ashrafizadeh and Kamran 2010; Hasan et al. 2010; Abdurahman et al. 2012).

\subsubsection{Effect of shear rate}

The effect of shear rate on the percentage VR at 20,30,40, and $50 \mathrm{wt} \%$ input water fraction is presented in Fig. 6. It is clear that the VR for the water-in-oil emulsion (i.e., $20 \mathrm{wt} \%$ water) increased gradually with increasing shear rates and eventually reached a plateau where a further increase in shear rate had no effect on VR. For the oil-inwater emulsion, the gradual increase of VR with shear rate was not large. The VR reached a plateau for the whole range of shear rates. This is because the flow behavior of the emulsion is a strong function of the continuous phase. For the oil-in-water emulsion, since water was the continuous phase, the decrease in viscosity with shear rate was not significant due to the Newtonian behavior of the water phase. On the other hand, the emulsion viscosity was 


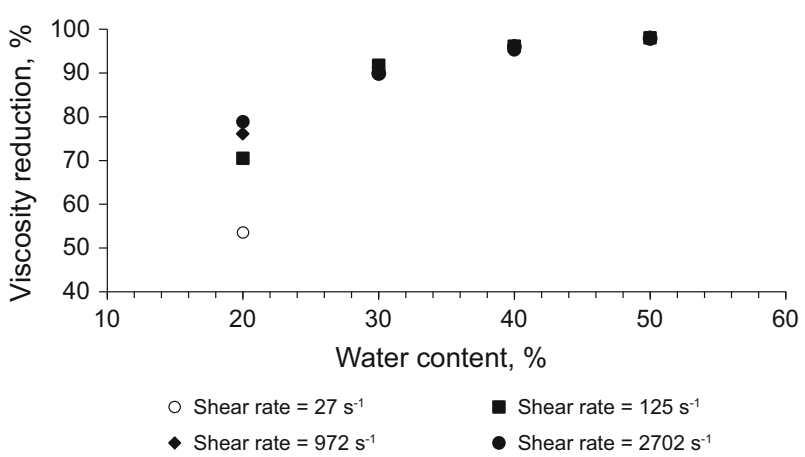

Fig. 5 Effect of water content at different shear rates on the viscosity reduction of Omani heavy crude oil emulsion $\left(30{ }^{\circ} \mathrm{C}, 3 \mathrm{wt} \%\right.$ surfactant concentration, 1,000 rpm mixing speed, $30 \mathrm{~min}$ mixing time)

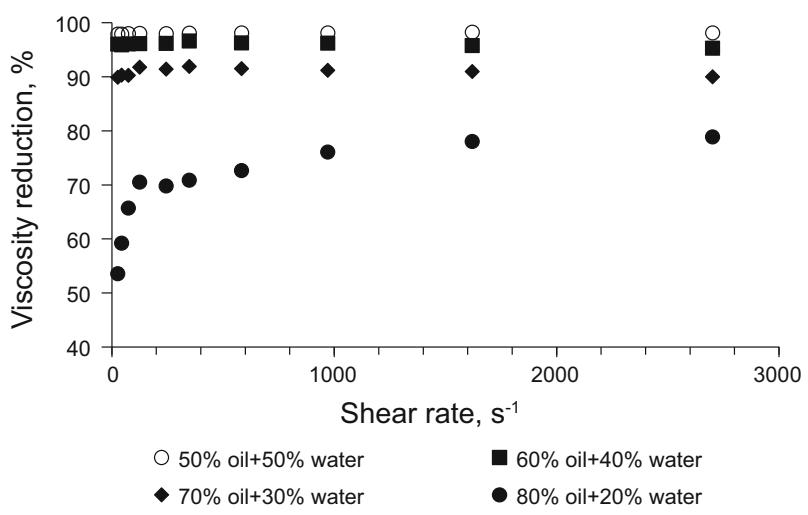

Fig. 6 Effect of shear rates at different water input fractions on the viscosity reduction of Omani heavy crude oil emulsion $\left(30{ }^{\circ} \mathrm{C}, 3 \mathrm{wt} \%\right.$ surfactant concentration, $1,000 \mathrm{rpm}$ mixing speed, $30 \mathrm{~min}$ mixing time)

observed to exhibit the shear thinning behavior of the continuous phase at $20 \mathrm{wt} \%$ water content (i.e., similar to that of oil as shown in Fig. 1).

\subsubsection{Effect of temperature}

The influence of temperature on the effectiveness of the emulsion prepared in this study was investigated by measuring the apparent viscosity at 20,30, 40, 50, 60, and $70{ }^{\circ} \mathrm{C}$. A comparison of the obtained results is presented in Figs. 7 and 8 for oil-in-water emulsion $(60 \%$ oil and $40 \%$ water) and water-in-oil emulsion (80\% oil and $20 \%$ water), respectively. Both figures reveal a decrease in VR as temperature increased. This was attributed to the decrease in crude oil viscosity with temperature (see Fig. 1). The reduction in viscosity was more pronounced at lower temperatures. For the oil-in-water emulsion of $60 \%$ oil and $40 \%$ water, it is observed that the VR varied from $83 \%$ at $70{ }^{\circ} \mathrm{C}$ to around $99 \%$ at $20{ }^{\circ} \mathrm{C}$. It is also noticed that the VR changed very little with shear rates at all the

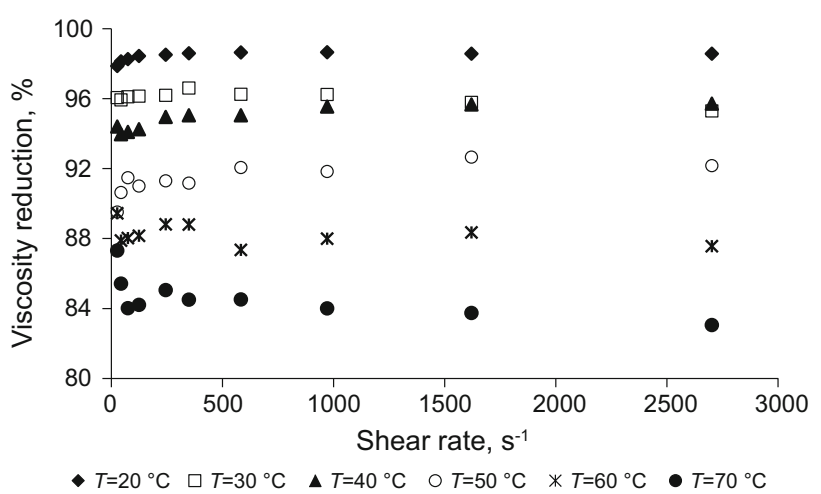

Fig. 7 Effect of shear rates at different temperatures on the viscosity reduction of stable oil-in-water emulsion $(60 \%$ oil $+40 \%$ water, $30{ }^{\circ} \mathrm{C}, 3 \mathrm{wt} \%$ surfactant concentration, $1,000 \mathrm{rpm}$ mixing speed, 30 min mixing time)

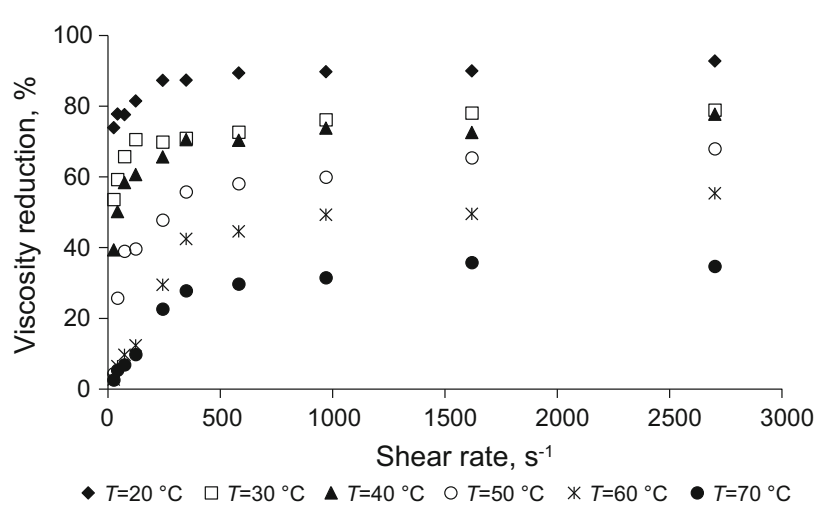

Fig. 8 Effect of shear rates at different temperatures on the viscosity reduction of stable water-in-oil emulsion $(80 \%$ oil $+20 \%$ water, $30{ }^{\circ} \mathrm{C}, 3 \mathrm{wt} \%$ surfactant concentration, $1,000 \mathrm{rpm}$ mixing speed, 30 min mixing time)

investigated temperatures (see Fig. 7). On the other hand, for the water-in-oil emulsion of $80 \%$ oil and $20 \%$ water, the VR varied in a wide range from $3 \%$ at $70{ }^{\circ} \mathrm{C}$ to around $90 \%$ at $20{ }^{\circ} \mathrm{C}$. This was also attributed to the viscosity of the continuous phase. The VR was also found to increase with shear rates until it reached a plateau at shear rates greater than $400 \mathrm{~s}^{-1}$ where a further increase in shear rates had no effect on VR (see Fig. 8).

\subsubsection{Effect of solid concentration}

Stable oil-in-water emulsion and water-in-oil emulsion might contain fine particles while flowing in pipelines. Therefore, it is important to understand the influence of solid particles on the VR of these emulsions. This effect was investigated using three different solid concentrations; $0.05,0.1$, and $0.2 \mathrm{wt} \%$. The VR at stable oil-in-water emulsion (60\% oil and $40 \%$ water) and stable water-in-oil emulsion (80\% oil and $20 \%$ water) with respect to shear rates is shown in Figs. 9 and 10. It is clear that the VR 


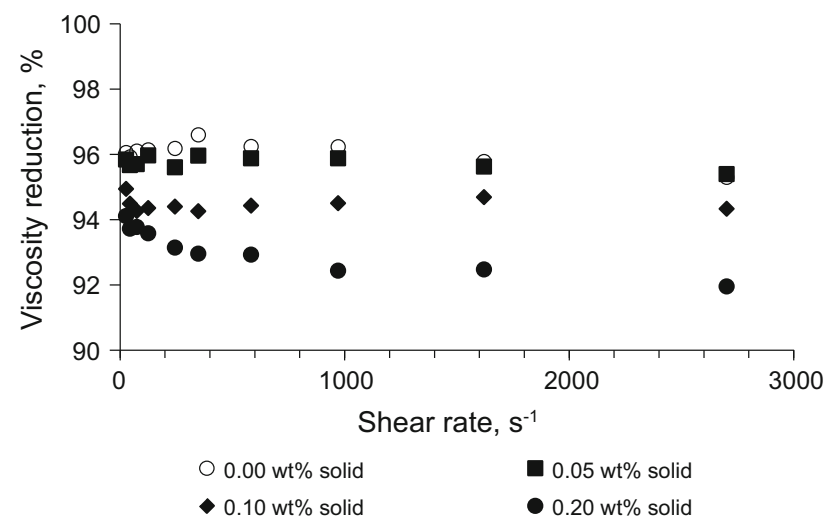

Fig. 9 Effect of shear rates at different solid concentrations on the viscosity reduction of stable oil-in-water emulsion $(60 \%$ oil $+40 \%$ water, $30{ }^{\circ} \mathrm{C}$, $3 \mathrm{wt} \%$ surfactant concentration, $1,000 \mathrm{rpm}$ mixing speed, 30 min mixing time)

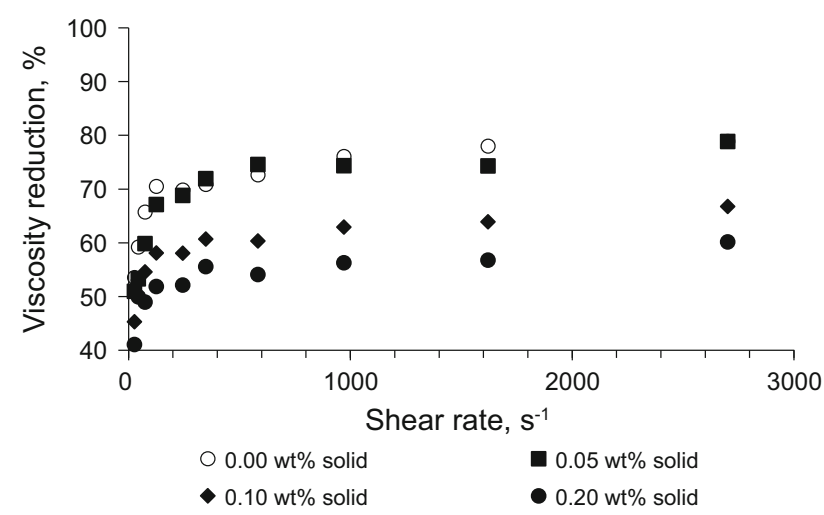

Fig. 10 Effect of shear rates at different solid concentrations on the viscosity reduction of stable water-in-oil emulsion $(80 \%$ oil $+20 \%$ water, $30{ }^{\circ} \mathrm{C}, 3 \mathrm{wt} \%$ surfactant concentration, 1,000 rpm mixing speed, 30 min mixing time)

decreased with an increase in solid concentration. The reason might be that the agglomeration of the solid particles increased, hence resulted in the decrease in VR of the emulsion. However, the decrease in VR for the oil-in-water emulsion was insignificant (less than $5 \%$ ) as shown in Fig. 9. On the contrary, the decrease in VR was pronounced for the water-in-oil emulsion and could be as high as $25 \%$ (see Fig. 10). This is also attributed to the continuous phase of the emulsion, since the flow behavior of the emulsion is a strong function of the continuous phase (see discussions in Sect. 3.3).

\section{Conclusions}

The VR induced by emulsifying Omani heavy crude oil using a non-ionic water soluble surfactant (Triton X-100) was experimentally investigated. The effects of water content, shear rate, temperature, and solid particles concentrations on the performance of the emulsion in reducing the viscosity of the crude were examined. Based on the experimental findings, the following can be concluded:

- The crude oil exhibits a shear thinning behavior where the apparent viscosity is found to decrease with shear rates for all the investigated temperatures. The strongest shear thinning was observed at $20{ }^{\circ} \mathrm{C}$ where the viscosity of the crude falls from 1,920 to $1,190 \mathrm{mPa} \mathrm{s}$ at shear rates of 27 and $349 \mathrm{~s}^{-1}$, respectively.

- The percentage viscosity reduction was found to increase with water content reaching a maximum value at around $50 \mathrm{wt} \%$ input water fraction. The emulsification was able to induce viscosity reduction for all the conditions investigated and regardless of the continuous phase.

- The percentage viscosity reduction was found to decrease with increasing the temperature and the solid concentrations of the emulsion.

- Two behaviors of viscosity reduction were observed with respect to shear rate. For water-in-oil emulsion, the viscosity reduction increased as shear rate increased and eventually reached a plateau at a shear rate of around $350 \mathrm{~s}^{-1}$. For oil-in-water emulsion, viscosity reduction remained almost constant as shear rate increased.

Open Access This article is distributed under the terms of the Creative Commons Attribution License which permits any use, distribution, and reproduction in any medium, provided the original author(s) and the source are credited.

\section{References}

Abdurahman NH, Rosli YM, Azhari NH, et al. Pipeline transportation of viscous crudes as concentrated oil-in-water emulsions. J Petrol Sci Eng. 2012;90-91:139-44.

Al-Wahaibi T, Angeli P. Experimental study on interfacial waves in stratified horizontal oil-water flow. Int $\mathrm{J}$ Multiph Flow. 2011;37(8):930-40.

Al-Wahaibi T, Yusuf N, Al-Wahaibi Y, et al. Experimental study on the transition between stratified and non-stratified horizontal oilwater flow. Int J Multiph Flow. 2012;38(1):126-35.

Angeli P, Hewitt GF. Flow structure in horizontal oil-water flow. Int J Multiph Flow. 2000;26(7):1117-40.

Ashrafizadeh SN, Kamran M. Emulsification of heavy crude oil in water for pipeline transportation. $J$ Petrol Sci Eng. 2010;71(3-4):205-11.

Ghannam MT, Esmail N. Flow enhancement of medium-viscosity crude oil. J Pet Sci Technol. 2006;24(8):985-99.

Gregoli AA, Hamshar JA, Olah AM, et al. Preparation of stable crude oil transport emulsions. 2006. US Patent no. 4725287.

Hasan SW, Ghannam MT, Esmail N. Heavy crude oil viscosity reduction and rheology for pipeline transportation. Fuel. 2010;89(5):1095-100.

Iona M. Process for producing low-density low sulfur crude oil. 1978. US Patent no. 4092238. 
Joseph DD, Bai R, Chen KP, et al. Core annular flows. Annu Rev Fluid Mech. 1997;29:65-90.

Langevin D, Poteau S, Hénaut I, et al. Crude oil emulsion properties and their application to heavy oil transportation. Oil Gas Sci Technol. 2004;59(5):511-21.

Lappin GR, Saur JD. Alpha olefins applications handbook. New York: CRC Press; 1989.

Lovick J, Angeli P. Experimental studies on the dual continuous flow pattern in oil-water flows. Int J Multiph Flow. 2004;30(1): 139-57.

Nädler M, Mewes D. Flow induced emulsification in the flow of two immiscible liquids in horizontal pipes. Int $\mathrm{J}$ Multiph Flow. 1997;23(1):55-68.

Paso K, Silset A, Sørland G, et al. Characterization of the formation, flowability, and resolution of Brazilian crude oil emulsions. Energy Fuels. 2009;23(1):471-80.

Rivas H, Gutierrez X, Cardenas AE, et al. Natural surfactant with amines and ethoxylated alcohol. 1998. US Patent 5792223.

Russell TWF, Charles ME. The effect of the less viscous liquid in the laminar flow of two immiscible liquids. Can J Chem Eng. 1959;37(1):18-24.
Sakka S. Sol-gel science and technology topics in fundamental research and applications., Sol-gel prepared ferroelectrics and related materialsNew York: Kluwer Academic Publisher; 2002. p. 33-5.

Saniere A, Hénaut I, Argillier JF. Pipeline transportation of heavy oils, a strategic, economic and technological challenge. Oil Gas Sci Technol. 2004;59(5):455-66.

Simon R, Poynter WG. Pipelining oil/water mixtures. 1970. US Patent 3519006.

Yaghi BM, Al-Bemani A. Heavy crude oil viscosity reduction for pipeline transportation. Energy Sources. 2002;24(2):93-102.

Yusuf N, Al-Wahaibi Y, Al-Wahaibi T, et al. Effect of oil viscosity on the flow structure and pressure gradient in horizontal oilwater flow. Chem Eng Res Des. 2012a;90(8):1019-30.

Yusuf N, Al-Wahaibi T, Al-Wahaibi Y, et al. Experimental study on the effect of drag reducing polymer on flow patterns and drag reduction in a horizontal oil-water flow. Int J Heat Fluid Flow. 2012b;37:74-80. 